\title{
A comprehensive model to study nonlinear behavior of multilayered micro beam switches
}

Ghader Rezazadeh · Hamed Sadeghian •

Ebrahim Abbaspour

Published online: 3 May 2007

(C) Springer-Verlag 2007

\section{Erratum to: Microsyst Technol \\ DOI 10.1007/s00542-007-0398-x}

Unfortunately, the authors Hamed Sadeghian and Ebrahim Abbaspour were omitted in the original version of this article. Their names and affiliations are shown here.

The online version of the original article can be found at http://dx.doi.org/10.1007/s00542-007-0398-x.

G. Rezazadeh $(\bowtie) \cdot$ E. Abbaspour

Mechanical Engineering Department,

Urmia University, $1.5 \mathrm{~km}$ Sero Road,

Urmia, Azerbaijan 57159-165, Iran

e-mail: g.rezazadeh@mail.urmia.ac.ir

H. Sadeghian

Faculties of EEMCS and 3ME,

Departments of ET and PME,

Technical University of Delft,

Delft, The Netherlands

e-mail: H.Sadeghianmarnani@tudelft.nl 